\title{
Formation and Investigation of Physicochemical, Biological and Bacteriostatic Properties of Nanocomposite Foils Containing Silver Nanoparticles and Graphene Oxide in Hyaluronic Acid Matrix
}

\author{
Karen Khachatryan ${ }^{1, * \mathbb{D}}$, Lusine Khachatryan ${ }^{2}$, Marcel Krzan ${ }^{3, * \mathbb{D}}$, Magdalena Krystyjan ${ }^{1}$ (D), \\ Lidia Krzemińska-Fiedorowicz ${ }^{1}$, Anna Lenart-Boroń ${ }^{4}{ }^{\mathbb{D}}$, Aneta Koronowicz ${ }^{1}$, Mariola Drozdowska ${ }^{1}$ (D) and \\ Gohar Khachatryan ${ }^{1}$ (D)
}

1 Faculty of Food Technology, University of Agriculture in Krakow, Balicka Street 122, 30-149 Krakow, Poland; magdalena.krystyjan@urk.edu.pl (M.K.); lidia.krzeminska-fiedorowicz@urk.edu.pl (L.K.-F.); aneta.koronowicz@urk.edu.pl (A.K.); mariola.drozdowska@urk.edu.pl (M.D.); gohar.khachatryan@urk.edu.pl (G.K.)

2 Clinical Department of Orthopedics and Traumatology, University Hospital in Krakow, Macieja Jakubowskiego 2, 30-688 Kraków, Poland; lusine93@gmail.com

3 Jerzy Haber Institute of Catalysis and Surface Chemistry, Polish Academy of Sciences, Niezapominajek 8 , 30-239 Krakow, Poland

check for updates

Citation: Khachatryan, K.; Khachatryan, L.; Krzan, M.; Krystyjan, M.; KrzemińskaFiedorowicz, L.; Lenart-Boroń, A.; Koronowicz, A.; Drozdowska, M.; Khachatryan, G. Formation and Investigation of Physicochemical, Biological and Bacteriostatic

Properties of Nanocomposite Foils Containing Silver Nanoparticles and Graphene Oxide in Hyaluronic Acid Matrix. Materials 2021, 14, 3377. https://doi.org/10.3390/ma14123377

Academic Editor: Francesco Baino

Received: 29 May 2021

Accepted: 15 June 2021

Published: 18 June 2021

Publisher's Note: MDPI stays neutral with regard to jurisdictional claims in published maps and institutional affiliations.

Copyright: (c) 2021 by the authors. Licensee MDPI, Basel, Switzerland. This article is an open access article distributed under the terms and conditions of the Creative Commons Attribution (CC BY) license (https:/ / creativecommons.org/licenses/by/ $4.0 /)$.
4 Faculty of Agriculture and Economics, University of Agriculture in Krakow, Mickiewicz Ave. 21, 31-120 Krakow, Poland; anna.lenart-boron@urk.edu.pl

* Correspondence: karen.khachatryan@urk.edu.pl (K.K.); marcel.krzan@ikifp.edu.pl (M.K.)
Abstract: Natural polysaccharides, including hyaluronic acid, find a wide range of applications in biomedical sciences. There is a growing interest in nanocomposites containing hyaluronic acid and nanoparticles such as nanometals or graphene. In this study, we prepared foils of pure sodium hyaluronate and sodium hyaluronate containing nanosilver, graphene oxide, nanosilver/graphene oxide and characterized their properties. UV-vis spectroscopy and scanning electron microscopy (SEM) confirmed the formation of 10-20 nm silver nanoparticles. The structural changes were investigated using Fourier transforms infrared (FTIR) spectra and size exclusion chromatography. The obtained results suggest changes in molecular weights in the samples containing nanoparticles, which was highest in a sample containing nanosilver/graphene oxide. We also assessed the mechanical properties of the foils (thickness, tensile strength and elongation at break) and their wettability. The foils containing nanosilver and nanosilver/graphene oxide presented bacteriostatic activity against E. coli, Staphylococcus spp. and Bacillus spp., which was not observed in the control and sample containing graphene oxide. The composites containing graphene oxide and nanosilver/graphene oxide exhibited a cytotoxic effect on human melanoma WM266-4 cell lines (ATCC, Manassas, VA, USA).

Keywords: silver nanoparticles; graphene; hyaluronic acid; bacteriostatic properties; cytotoxic effect

\section{Introduction}

Polysaccharides are commonly available and biodegradable raw materials attractive to various industries (such as chemical or food technology, medicine, pharmaceutics). The interest in natural polysaccharides is increasing due to their expanding potential applications [1]. The key parameters for their practical use are low, medium, and high molecular weights, variable polydispersity, forming linear and branched macrostructures, monofunctionality, high degree of chirality, either low or high aqueous solubility, low (if any) toxicity, and immunogenicity. The bioactivity of polysaccharides and their antioxidative, immunomodulating, anti-inflammatory, antiviral, antimutagenic, cancerostatic and anticlotting properties motivate their application in nanotechnology, medicine, and food technology [2-6]. In recent years, various polysaccharides have been used in the synthesis 
of inorganic nanoparticles, acting as reducers and stabilizers and providing the formation of nanoparticles of uniform size [7-10]. The following polysaccharides are suitable for developing nanoparticles: starch, cellulose, alginates, pectins, xanthan gum, cyclodextrins, chitosan, heparin, and hyaluronic acid [11-13].

Hyaluronic acid is a polymer of D-glucuronic acid and N-acetyl-D-glucosamine that is widely spread in nature. Although it resides mainly in intercellular matrices of vertebrates, it can also be found in the organisms of certain bacteria (Aerobacter aerogenes and Streptococcus pyogenes] [14]. It also resides in the human organism as a component of so-called Wharton's jelly, skin, synovial fluid, and the eye's vitreous. Hyaluronic acid plays an essential role in embryo development, tissue growth, angiogenesis, wound healing, and controls the biomechanical properties of tissues. For these properties, hyaluronic acid has found several applications in tissue engineering, cosmetology, and various fields of medicine. Because of its anionic character, hyaluronic acid has a remarkable water binding capacity and is suitable for hydrogel production. In vitro studies showed that this polysaccharide positively influences cell migration and building extracellular substances. Depending on the molecular mass and additional functional groups it can either stimulate or inhibit various paths and processes within living organisms, including those associated with tumors [15].

Graphenes and their derivatives are single-layered carbon materials. The large surface area on both sides of the sheet is provided by their unique 2D structure and enables physical adsorption of nucleobases and aromatic compounds, mainly through $\pi-\pi$ stacking. Various functional groups with different polarities and ionic characters (hydroxyl, epoxy and carboxyl groups) present in graphene oxide (GO) sheets give an opportunity to create new materials by interactions with biomolecules [16]. Recently, they have attracted considerable interest from biomedical researchers.

Although GO is monodisperse in pure water, its aggregation occurs in highly concentrated solutions of salts or proteins, for example, culture medium and serum. Different functional groups have been added to GO to make it more stable and biocompatible in the aqueous phase. Hydrophilic groups, such as poly(ethylene glycol) sulfonic acid groups and polysaccharides, make GO more promising in many fields, for example, in drug delivery [17-22].

Jung et al. successfully prepared a nanographene oxide-hyaluronic acid (NGO-HA) conjugate. Because of its structure and properties, it could be used to target specific drug delivery via HA-receptor-mediated endocytosis. The $\mathrm{pH}$-dependent drug release and target specific anti-cancer effect was confirmed by in vitro tests [23]. Another study, performed by Song et al. [24] presented the synthesis and properties of a novel nanohybrid of hyaluronic acid (HA)-decorated graphene oxide (GO), fabricated as a targeted and $\mathrm{pH}$-responsive drug delivery system. The obtained nanohybrid was successfully tested for controlling the release of the anti-cancer drug doxorubicin (DOX) and it was confirmed that the HA-GO-DOX nanohybrids have potential clinical applications for anti-cancer drug delivery. Dantas et al. prepared a nanohybrid composed of GO functionalized with HY; it was tested in vitro and in vivo and proved to accelerate the tissue regeneration process in bone defects created in the tibia of rats [25].

Graphene, as other nanoparticles, exhibits a tendency to aggregation via the Van der Waals interaction between its layers and such behavior limits its applications. Metal nanoparticles introduced onto the graphene surface prevent aggregation and provide good photoconductivity and catalytic properties of the graphene/metal nanocomposites [26]. Good conductivity, strong ultraviolet-visible absorption ability, and catalytic activity of silver nanoparticles are why they are popular in many fields, such as for use in electronic devices, as biomarkers, and as antibacterial agents [27]. Recently, the interest in graphene/metal nanoparticle composites has been growing, especially in catalysis, energy storage, chemical sensors, and hydrogen storage [28].

Polymeric nanocomposites with nanosilver particles sized from 1 to $100 \mathrm{~nm}$ evoke considerable interest in biomedical sciences. Depending on the size of those particles, that 
is, their surface to volume ratio, they exhibit different biological, chemical, and physical properties [29] — among them, the most essential for biological sciences are bactericidal and fungicidal properties. The morphology and stability of silver nanoparticles depend on the mode of their preparation [30], applied reducer, and stabilizing reagent.

Due to the emergence and increase in the number of antimicrobial resistant, as well as multidrug resistant, microorganisms [31], including typically environmental species of bacteria [32], new efficient and cost-effective antimicrobial agents that would overcome this resistance are sought [31]. Nanoparticles are now considered a reasonable alternative to antimicrobial agents and seem to have the potential to solve the problem of multidrug resistance among bacteria [33]. A number of studies have been published to date, demonstrating the antimicrobial potential of silver nanoparticles obtained using various methods [34-36], thus making them promising agents not only for fighting infections but in many other biomedical areas [33]. The studies performed by Khachatryan et al. [37,38] presented the green synthesis of silver nanoparticles using hyaluronan as a stabilizing template. The obtained composites exhibited bacteriostatic activity, water solubility, and promising physicochemical and functional properties.

In this study, we prepared four types of foils containing pure sodium hyaluronate (Hyal/C), nanosilver in Hyal matrix (Hyal/Ag), graphene oxide in Hyal matrix (Hyal/GO) and nanosilver with graphene oxide in Hyal matrix (Hyal/Ag/GO) using environmentallyfriendly methods. We also characterized their morphologies, and physicochemical and biological properties.

\section{Materials and Methods}

\subsection{Materials}

Sodium hyaluronate (Sigma-Aldrich, Poznan, Poland, PubChem CID: 3084049), $\mathrm{AgNO}_{3}$ (Aldrich, Poznan, Poland, 99.99\%, PubChem CID: 24470), $\mathrm{NH}_{3}$ (Sigma-Aldrich, Poznan, Poland, PubChem CID: 18944693) and D-(+)-xylose (Sigma-Aldrich, Poznan, Poland, BioXtra, PubChem CID: 135191) and deionized water were applied for the preparation of composites with nano Ag.

\subsection{Preparation of Nanoparticles Composites}

\subsubsection{Preparation of Hyal/C Foils}

Aq. sodium hyaluronate $(0.8 \mathrm{~g}$ in $80 \mathrm{~mL}$ water $)$ was maintained at $30{ }^{\circ} \mathrm{C}$ under continuous stirring. The resulting homogeneous and transparent gel was divided into two equal parts-one half (for the assessment of mechanical, structural and antibacterial properties) was applied to a clean polypropylene surface and dried at $50{ }^{\circ} \mathrm{C}$ to constant weight and the dry foils were then collected and stored in closed vessels. The remaining gel was used for the cytotoxicity tests.

\subsubsection{Preparation of Hyal/Ag Composite}

The nanocomposite was prepared according to the described procedure [37]. Aq. sodium hyaluronate $(0.8 \mathrm{~g}$ in $80 \mathrm{~mL}$ water $)$ was maintained at $30^{\circ} \mathrm{C}$ under continuous stirring. Aq. $\mathrm{AgNO}_{3}$ solution $(1.5 \mathrm{~g}$ in $100 \mathrm{~mL}$ water) $(0.6 \mathrm{~mL})$ was then introduced followed by addition of $4 \% w / w$ aq. ammonia $(2 \mathrm{~mL}), 4 \% w / w$ aq. xylose $(8 \mathrm{~mL})$. The reaction mixture was then agitated for $30 \mathrm{~min}$ with magnetic stirrer at $60{ }^{\circ} \mathrm{C}$ in a thermostatic water bath. The resulting suspension of nanoAg in the Hyal matrix was lowered to room temperature and then centrifuged (5000 rpm). The gel was divided into two equal partsone half (for the assessment of mechanical, structural, and antibacterial properties) was applied to a clean polypropylene surface and dried at $50{ }^{\circ} \mathrm{C}$ to constant weight and the dry foils were collected and stored in closed vessels. The remaining gel was used for the cytotoxicity tests. 


\subsubsection{Preparation of Hyal/GO Composite}

Graphene oxide (GO) was synthesized using the modified Hummers method [39]. Aqueous suspensions containing $0.1 \%$ of GO in distilled water were prepared and treated using ultrasounds.

Sodium hyaluronate powder $(0.8 \mathrm{~g})$ was added to a deionized then distilled water $(80 \mathrm{~mL})$ and maintained at $30^{\circ} \mathrm{C}$ under constant stirring. After stirring the reaction mixture, $4 \mathrm{~mL}$ of the suspension of $\mathrm{GO}(0.1 \%)$ was added and then mixed for $2 \mathrm{~h}$, followed by cooling to room temperature and then it was centrifuged (5000 rpm). The gel was divided into two equal parts-one half (for the assessment of mechanical, structural and antibacterial properties) was applied to a clean polypropylene surface and dried at $50^{\circ} \mathrm{C}$ to constant weight and the dry foils were collected and stored in closed vessels. The remaining gel was used for the cytotoxicity tests.

\subsubsection{Preparation of Hyal/Ag/GO Composite}

Sodium hyaluronate powder $(0.8 \mathrm{~g})$ was added to a deionized then distilled water $(80 \mathrm{~mL})$ and maintained at $30^{\circ} \mathrm{C}$ under constant stirring. Aq. $\mathrm{AgNO}_{3}$ solution $(1.5 \mathrm{~g}$ in $100 \mathrm{~mL}$ water) $(0.6 \mathrm{~mL})$ was introduced followed by the addition of $4 \% w / w$ aq. ammonia $(2 \mathrm{~mL}), 4 \% w / w$ aq. xylose $(8 \mathrm{~mL})$. That reaction mixture was then agitated for $30 \mathrm{~min}$ with a magnetic stirrer at $60{ }^{\circ} \mathrm{C}$ in a thermostatic water bath. After stirring the reaction mixture, $4 \mathrm{~mL}$ of the suspension of $\mathrm{GO}(0.1 \%)$ was added and then mixed for $2 \mathrm{~h}$, followed by cooling to room temperature. The gel was divided into two equal parts-one half (for the assessment of mechanical, structural and antibacterial properties) was applied to a clean polypropylene surface and dried at $50{ }^{\circ} \mathrm{C}$ to constant weight and the dry foils were collected and stored in closed vessels. The remaining gel was used for the cytotoxicity tests.

The resulting flexible and transparent films are shown in Figure 1.

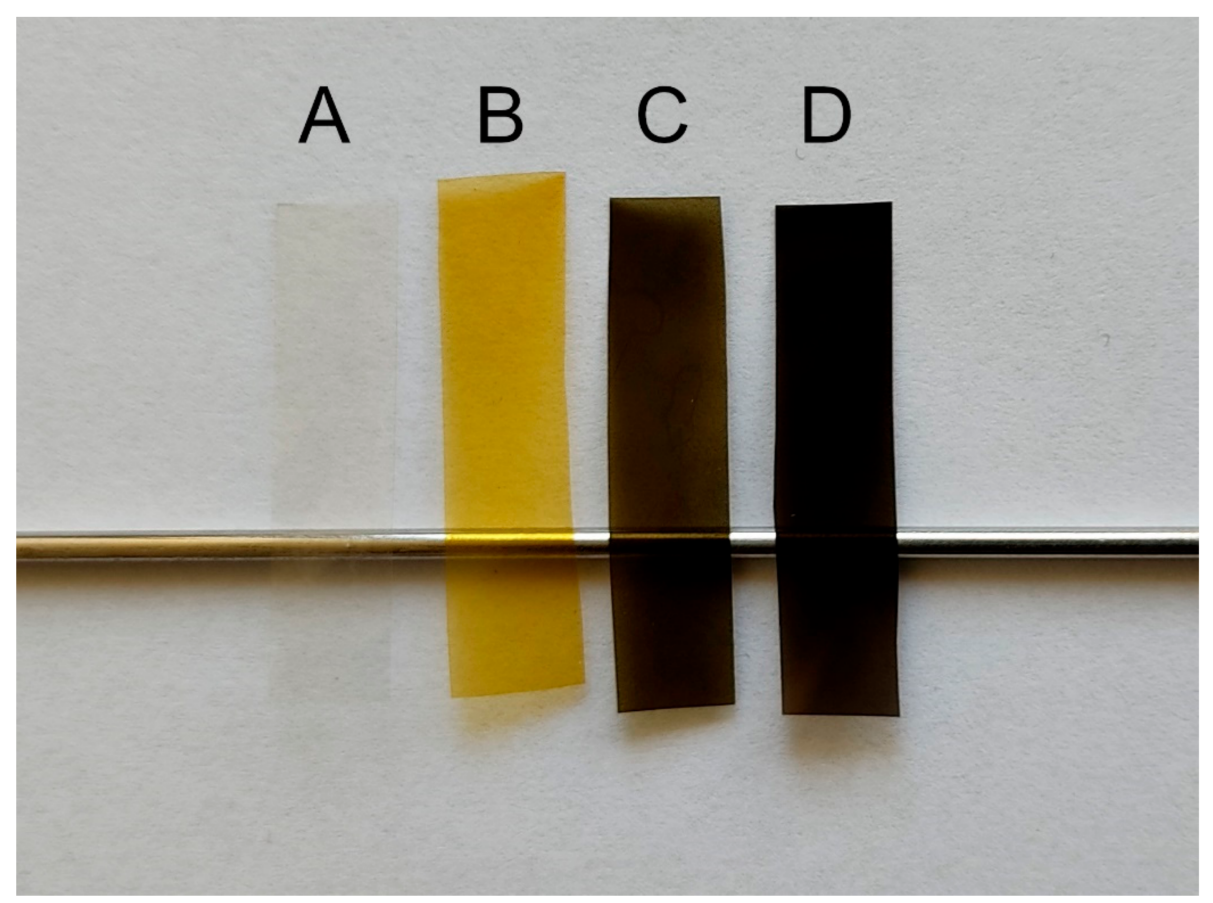

Figure 1. Obtained foils: A-Hyal/C; B-Hyal/Ag; C-Hyal/Ag/GO; D-Hyal/GO.

\subsection{Characterization of Nanoparticle Composites}

2.3.1. Determination of Molecular Weight MW and Radii of Gyration Rg of Starch Polysaccharide Molecules

A high-performance size exclusion chromatography (HPSEC) system with a multiangle laser light scattering (MALLS) detector and a differential refractive index detector (RI) were used to determine the molecular weight and radii of gyration of the starch polysac- 
charide molecules. The high-performance size exclusion chromatography (HPSEC) system consisted of a pump (Ultimate 3000, Dionex, Palo Alto, CA, USA), an injection valve (model 7021, Rheodyne, Palo Alto, CA, USA), a guard column (TSK PWH, Tosoh Corporation, Tokyo, Japan) and two connected size exclusion columns: TSKgel GMPWXL (300 mm $\times$ $7.8 \mathrm{~mm}$, Tosoh Corporation, Tokyo, Japan) and TSKgel 2500 PWXL (300 mm $\times 7.8 \mathrm{~mm}$, Tosoh Corporation, Tokyo, Japan). A multiangle laser light scattering (MALLS) detector (Dawn-DSP-F, Wyatt Technology, Santa Barbara, CA, USA) and a differential refractive index detector (model SE71, Shodex, Tokyo, Japan) were connected to the columns.

The flow rate of the mobile phase and the sample injection volume were $0.4 \mathrm{~mL} \cdot \mathrm{min}^{-1}$ and $500 \mu \mathrm{L}$, respectively. Calculation of the weight-average molecular weight (Mw) and radius of gyration $(\mathrm{Rg})$ were performed using Astra 4.70 software (Wyatt Technology, Santa Barbara, CA, USA).

\subsubsection{UV-Vis Absorption Spectrophotometry}

The UV-vis absorption spectra of the composites was recorded using a Shimadzu 2101 scanning spectrophotometer in the range of $200-700 \mathrm{~nm}$ using $10 \mathrm{~mL}$ cells (Hellma Materials $\mathrm{GmbH}$, Jena, Germany). Concentration of solution was $0.001 \mathrm{~g} / \mathrm{mL}$.

\subsubsection{Scanning and Transmission Electron Microscopy (SEM and TEM)}

The morphology of as-prepared nanocomposites was studied using a high resolution JEOL JSM - 7500 F (Akishima, Tokyo, Japan) field emission scanning electron microscope equipped with transmission electron detector (TED) and a retractable backscatteredelectron detector (RBEI).

\subsubsection{FTIR-ATR Spectrophotometry}

The FTIR-ATR spectra of the composites were recorded in the range of $4000-700 \mathrm{~cm}^{-1}$ using a MATTSON 3000 FT-IR (Madison, WI, USA) spectrophotometer. The instrument was equipped with a $30 \mathrm{SPEC} 30^{\circ}$ reflectance adapter fitted with the MIRacle ATR accessory from PIKE Technologies Inc., Madison, WI, USA.

\subsubsection{Thickness and Mechanical Properties of Composites}

The measurements were undertaken by using a micrometer, catalog no.: 805.1301 (Sylvac SA, Crissier, Switzerland), with a 0.001-mm resolution. The thickness was expressed as an average of 10 random measurements.

The samples for mechanical analyses were prepared according to Polish standards (PN-EN ISO 527-1:2012) and determined using the TA-XT plus texture analyzer (Stable Micro Systems, Haslemere, UK). Composites were cut into $35 \mathrm{~mm} \times 6 \mathrm{~mm}$ stripes and put into holders. The initial grip separation between holders was $20 \mathrm{~mm}$ and the rate of grip separation was $2 \mathrm{~mm} / \mathrm{min}$. Tensile strength (TS) was calculated by dividing tensile force (maximum force at rupture of the film) by the cross-sectional area of the film. The elongation percentage at break (E) was calculated by dividing the elongation at rupture by the initial gauge length and multiplying by 100 . The reported results were the average values of ten replicates.

\subsubsection{Contact Angle Determination}

Contact angles were determined using a Kruss-DSA100M (Kruss GmbH, Hamburg, Germany). Distilled water and pure diiodomethane's contact angles were determined on the studied polysaccharide foil surfaces using the sessile drop method. The detailed methodology of the contact angle experiments and surface free energy analyses were presented in our previous paper [38]. We used the Owens-Wendt method [40], which is best for polymer property evaluation [41]. All measurements were performed in the environmental cell under constant temperature conditions $\left(22 \pm 0.3{ }^{\circ} \mathrm{C}\right)$ and humidity. For each foil sample, more than three successive tests were carried out. 


\subsubsection{Bacteriostatic Activity Assay}

Pure Culture Isolation and Identification of Tested Microorganisms

Samples of surface water $(1000 \mathrm{~mL})$ were collected from the Białka River (Bialka Tatrzanska, Poland) in sterile polypropylene bottles. The membrane filtration method was applied to isolate Escherichia coli (blue-green colonies on TBX agar, incubation at $44^{\circ} \mathrm{C}, 48 \mathrm{~h}$ ), while the serial dilution method was used to isolate mesophilic bacteria (Trypticase Soy Agar, $37^{\circ} \mathrm{C}, 48 \mathrm{~h}$ ) and Staphylococcus spp. (Chapman agar, $37^{\circ} \mathrm{C}, 48 \mathrm{~h}$ ). After incubation, the selected bacterial colonies were subcultured, subjected to Gram staining and the systematic positions of 17 colonies of presumptive E. coli, Staphylococcus spp. and Bacillus spp. were verified by MALDI-TOF (matrix-assisted laser desorption/ionization-time of flight) mass spectrometry.

Bacteriostatic Activity of Nanoparticles

In order to test the bacteriostatic activity of the examined nanoparticles, bacterial isolates were transferred into sterile saline solutions to prepare 0.5 MacFarland suspension standards, which were then streaked onto Mueller-Hinton II agar (BTL, Lodz, Poland). The 5 -mm diameter disks of sterile foils were cut with a surface-sterilized scalpel and put onto the surface of the bacterial cultures. Foils without nanoparticles were used as a control. The plates were incubated at $35{ }^{\circ} \mathrm{C}$ for $18-24 \mathrm{~h}$. After this time, the results were read, i.e., the diameters of inhibition of microbial growth around the nanoparticle foil discs were evaluated and measured. The larger the diameter of the inhibition zone, the stronger the bacteriostatic effect.

\subsubsection{Cell Culture}

Human melanoma WM266-4 (ATCC ${ }^{\circledR}$ CRL-1676 ${ }^{\mathrm{TM}}$; malignant melanoma) cell lines were purchased from the American Type Culture Collections (ATCC, Manassas, VA, USA). Cells were cultured in controlled conditions (temp. $37^{\circ} \mathrm{C}, 95 \%$ humidity, $5 \% \mathrm{CO}_{2}$ ) according to the ATCC protocol in RPMI 1640 medium (Sigma-Aldrich, St. Louis, MO, USA) with the addition of $10 \%$ FBS (Sigma-Aldrich, St. Louis, MO, USA).

\subsubsection{Cell Treatment}

Cells were seeded on the 96 -well plates $(8 \times 103$ cells per well). Twenty-four hours after seeding, the growth medium was replaced with a medium containing nanoparticle composites at concentrations ranging from 15 to $35 \%$. Cells were treated for 24 and $48 \mathrm{~h}$. Untreated cells in the growth medium were considered as a negative control (UC). Each treatment included three biological and three technical replicates.

\subsubsection{Cytotoxicity and Viability Assay}

Concentrations of nanoparticle composites were selected based on their EC10 characteristics and confirmed using a Cytotoxicity LDH Test (Roche, Warsaw, Poland), according to the manufacturer's protocols. Cell viability was determined by a Crystal Violet Assay (Sigma-Aldrich, St. Louis, MO, USA).

\subsubsection{Statistical Analysis}

All experiments were performed at least three separate times and measured in triplicate. A Shapiro-Wilk's test was applied to assess the normality of distribution. An independent samples $t$-test was applied to compare unpaired means between two groups. $p<0.05$ was considered statistically significant. All analyses were performed using Statistica ver.13.1 (StatSoft, Tulsa, OK, USA).

\section{Results and Discussion}

In order to confirm the presence of silver nanoparticles and determine their size and the dispersion of graphene within the bionanocomposite, we performed scanning electron microscopy using a SEM equipped with transmission electron (TED) and retractable backscattered-electron (RBEI) detectors. Figure 2 presents microscopy images 
of Hyal/GO and Hyal/Ag/GO nanocomposites. As shown in the figure, the presence of regularly spaced black sheets indicates that $\mathrm{GO}$ has been uniformly dispersed throughout the nanocomposite film and that GO does not aggregate in the polysaccharide matrix. We also observe the bubble-like surface of the Hyal/Ag/GO sample, which may be caused by the formation of nanocapsules (or nano-bubbles), sized 50-100 nm, during the generation of nanosilver due to the interaction of Hyal with nanosilver and graphene flakes [42].

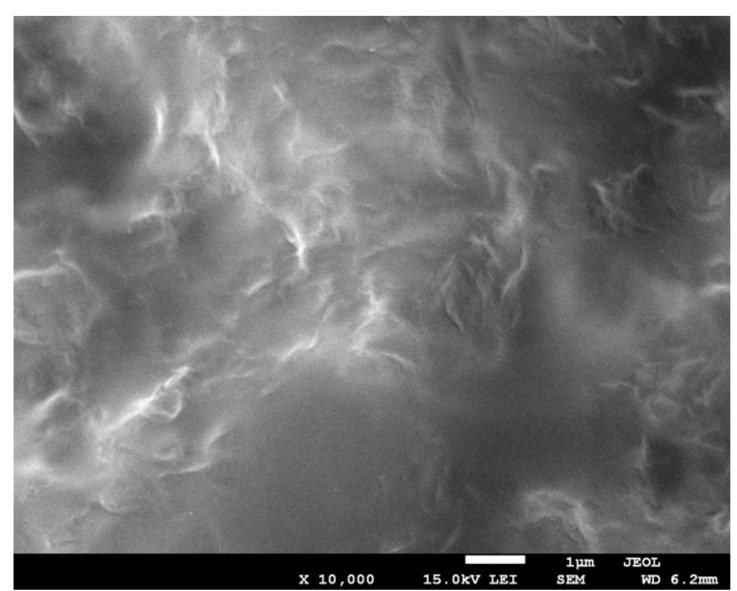

(a)

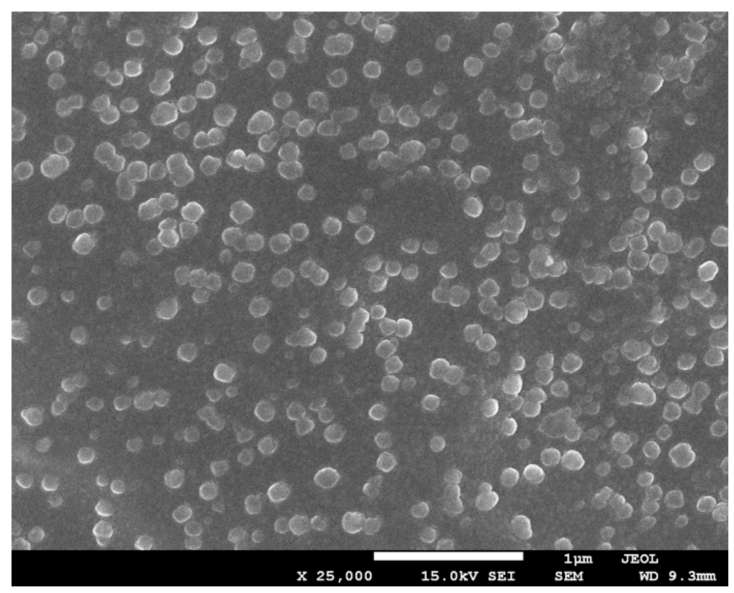

(c)

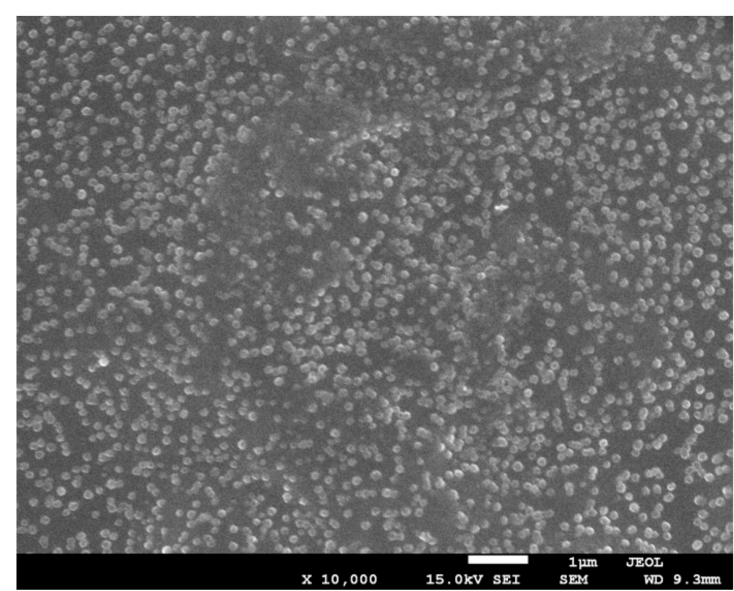

(b)

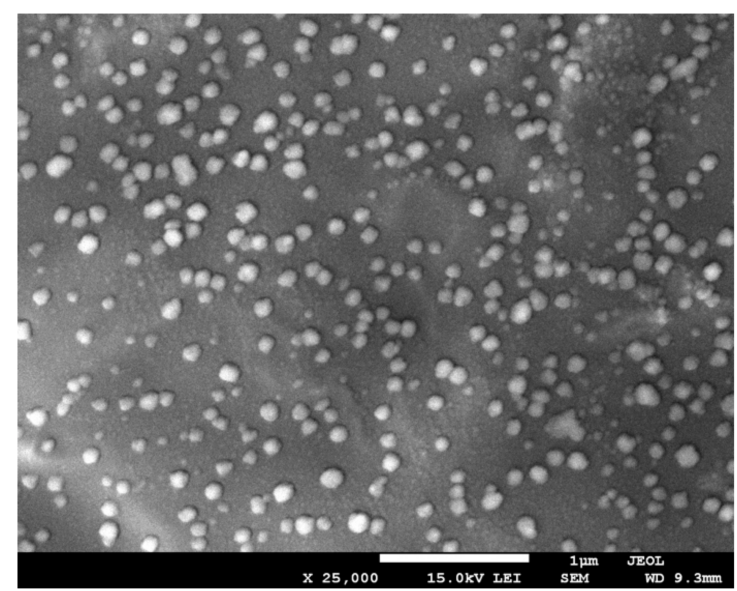

(d)

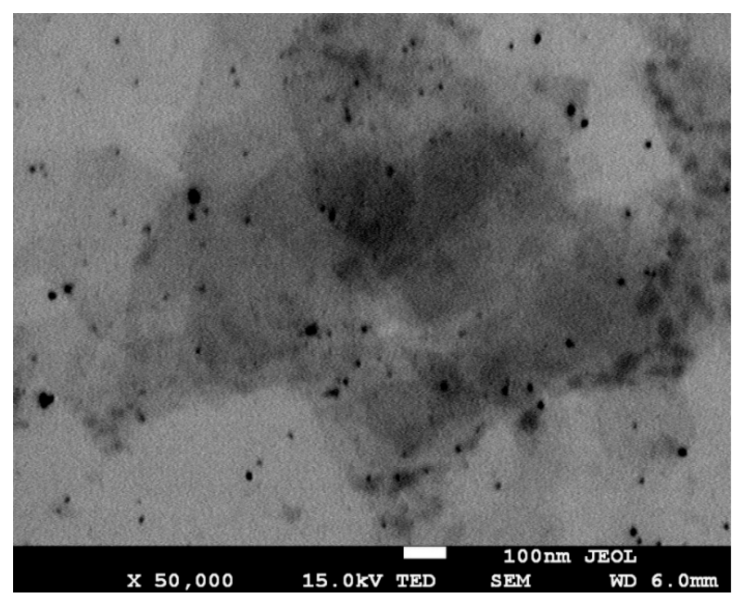

(e)

Figure 2. SEM (a-d) and TEM (e) micrographs of foils taken at different magnifications: (a) Hyal/GO; (b) Hyal/Ag/GO; (c) $\mathrm{Hyal} / \mathrm{Ag} / \mathrm{GO}$ at $\times 25,000$ magnification; (d) Hyal/Ag/GO at $\times 25,000$ magnification using secondary electron detection (COMPO system); (e) Hyal/ Ag/GO at $\times 50,000$ magnification. 
We used a secondary electron detection (COMPO system), to assess the distribution of nanosilver in the composites-we observed that silver nanoparticles were located inside the bubbles and were evenly distributed. Using a TED detector, we managed to define the size and shape of silver nanoparticles. The obtained silver nanostructures were characterized by different sizes, ranging $10-20 \mathrm{~nm}$, and they were regular, spherical, and the same as the silver nanoparticles obtained in Hyal matrix described in our previous papers $[37,38]$ which means that the presence of GO did not affect the size or shape of silver nanoparticles.

Size exclusion chromatography results are presented in Table 1 . We can observe an increase of the molecular weight in the samples containing nanoparticles. The highest increase was observed after the generation of Ag nanoparticles in the composite containing graphene oxide. We could also notice an increase in the radii of gyration in nanomaterial solutions compared to Hyal/C. This observation can be explained by interactions between hyaluronic acids, graphene oxide and nanometals.

Table 1. The average molecular weight $(\mathrm{Mw})$ and radius of gyration $(\mathrm{Rg})$ of $\mathrm{Hyal} / \mathrm{C}, \mathrm{Hyal} / \mathrm{Ag}$, $\mathrm{Hyal} / \mathrm{GO}$, and $\mathrm{Hy}-\mathrm{al} / \mathrm{Ag} / \mathrm{GO}$.

\begin{tabular}{ccc}
\hline Sample & Mw (Da) & Rg (nm) \\
\hline Hyal/C & $1.865 \times 10^{5}$ & 49.4 \\
Hyal/Ag & $4.090 \times 10^{5}$ & 58.5 \\
Hyal/GO & $4.768 \times 10^{5}$ & 50.5 \\
Hyal/Ag/GO & $5.046 \times 10^{5}$ & 52.8 \\
\hline
\end{tabular}

The FTIR-ATR spectra in the spectral range of $700-4000 \mathrm{~cm}^{-1}$ for GO and Hyal/C, Hyal/Ag, Hyal/Ag/GO films are presented in Figure 3a. GO displayed characteristic FTIR peaks corresponding to its oxygen functionalities, including the $\mathrm{C}=\mathrm{O}$ stretching vibration peak at $1731 \mathrm{~cm}^{-1}$, the $\mathrm{C}-\mathrm{O}$ (epoxy) stretching vibration peak at $1227 \mathrm{~cm}^{-1}$, the $\mathrm{C}-\mathrm{O}$ (alkoxy) stretching vibration peak at $1065 \mathrm{~cm}^{-1}$, and the vibration and deformation peaks of $\mathrm{O}-\mathrm{H}$ groups at 3412 and $1627 \mathrm{~cm}^{-1}$, respectively.

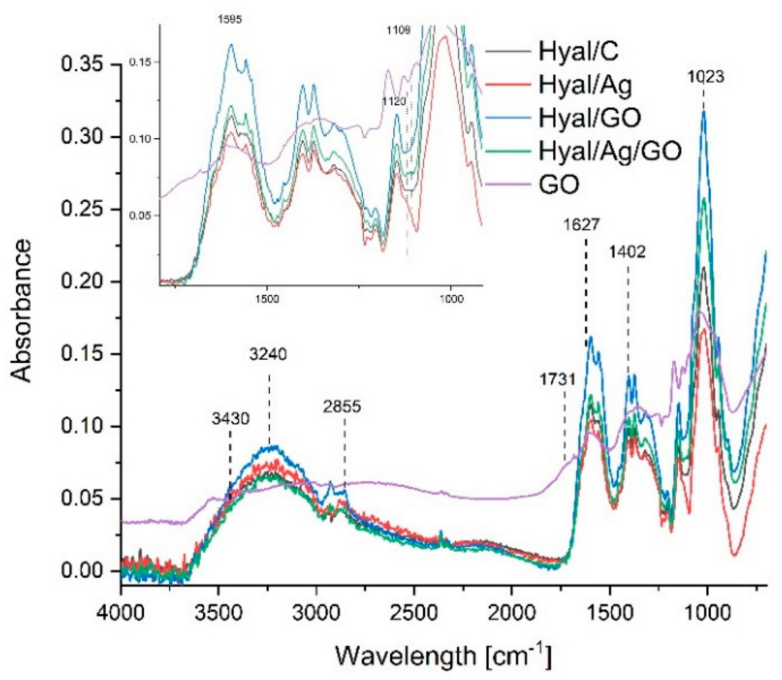

(a)

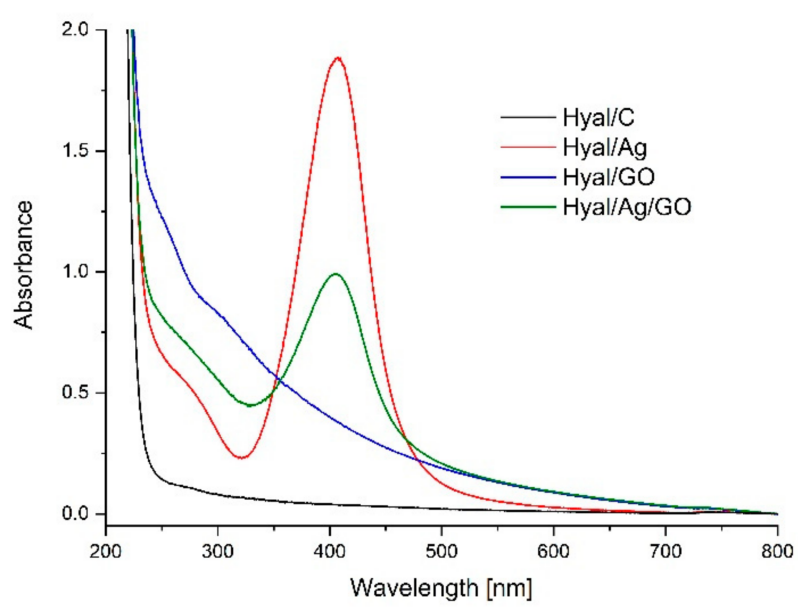

(b)

Figure 3. (a) FTIR spectra of Hyal/C (black line), Hyal/Ag (red line), Hyal/GO (blue line) and Hyal/Ag/GO (green line); (b) UV-vis spectra of Hyal/C (black line), Hyal/Ag (red line), Hyal/GO (blue line), Hyal/Ag/GO (green line) and GO (pink line).

The FTIR spectrum of Hyal showed the following characteristic bands: the peak located at $3240 \mathrm{~cm}^{-1}$ is associated with the intra-and intermolecular stretching vibration of the $-\mathrm{OH}$ group and the stretching vibration of the hydrogen bond from the $-\mathrm{NH}-$ group. 
The band at $2855 \mathrm{~cm}^{-1}$ can be attributed to the stretching vibration of the $-\mathrm{CH}_{2}$ - group; the band at about $1601 \mathrm{~cm}^{-1}$ corresponds to the amide carbonyl and the band at $1402 \mathrm{~cm}^{-1} \mathrm{can}$ be attributed to the stretching of the COO- group; the peak from $1023 \mathrm{~cm}^{-1}$ is attributed to the linkage stretching of $\mathrm{C}-\mathrm{OH}$. There are a very limited number of changes in the spectrum of Hyal/C and nanocomposite films. The Hyal/Ag/GO spectrum changes (decrease of the intensity of absorbance and no band shifts compared to Hyal/GO) suggest intermolecular interactions between the hydroxyl, carboxyl, amide carbonyl groups with silver nanoparticles and the absence of new covalent bonds.

The UV-Vis absorption spectra of Hyal/C, Hyal/Ag, Hyal/GO and Hyal/Ag/GO nanocomposites are presented in Figure $3 \mathrm{~b}$. There is a very large difference between the spectra of Hyal/C and the composites. GO spectrum presents a characteristic sharp absorption peak at about $233 \mathrm{~nm}$ and a broad shoulder at 290-305 nm, which is also clearly visible in the spectrum of Hyal/GO. The UV-Vis absorption spectra of the samples containing Hyal/Ag and Hyal/Ag/GO show an absorption band at 380-500 nm. These results point to the synthesis of $\mathrm{Ag}$ nanoparticles. The foils containing nanocomposites present higher absorbance compared to Hyal/C foil.

The effects of Ag and GO incorporation based on thickness, tensile strength (TS) and the elongation percentage at break (E) of hyaluronate composites are presented in Table 2. As was confirmed by statistical analysis, there were no differences in thickness between the composites. The tensile strength of Hyal composite was at a high level and was many times higher than composites made from other natural biodegradable polymers such as: starch [43,44], chitosan [45], cellulose acetate (CA) and cellulose nanofibers (CNF) [46].

Table 2. Mechanical properties of composites.

\begin{tabular}{cccc}
\hline Sample & $\begin{array}{c}\text { Thickness } \\
(\mathbf{m m})\end{array}$ & $\begin{array}{c}\text { TS } \\
(\mathbf{M P a})\end{array}$ & $\begin{array}{c}\text { E } \\
\mathbf{( \% )}\end{array}$ \\
\hline Hyal/C & $0.048 \pm 0.011^{\mathrm{a}}$ & $90.09 \pm 9.52^{\mathrm{a}}$ & $32.51 \pm 6.94^{\mathrm{a}}$ \\
Hyal/Ag & $0.051 \pm 0.008^{\mathrm{a}}$ & $81.27 \pm 5.05^{\mathrm{a}}$ & $14.14 \pm 3.75^{\mathrm{b}}$ \\
Hyal/GO & $0.049 \pm 0.001^{\mathrm{a}}$ & $69.30 \pm 3.57^{\mathrm{b}}$ & $13.99 \pm 3.88^{\mathrm{b}}$ \\
Hyal/Ag/GO & $0.050 \pm 0.009^{\mathrm{a}}$ & $57.80 \pm 7.00^{\mathrm{c}}$ & $5.11 \pm 1.54^{\mathrm{c}}$ \\
\hline
\end{tabular}

Parameters in columns denoted with the same letters $(a, b, c)$ do not differ statistically at the level of confidence $p<0.05$.

The addition of both, nanosilver and graphene particles weakened the tensile strength of the Hyal composites, however, in the case of Ag the difference was statistically insignificant. In the presence of GO, this parameter decreased by $23.1 \%$. The AG/GO combination had the most significant impact on the TS. According to Chen et al. [47], this fact may demonstrate the weak hydrogen-bonding interactions between biopolymer chains. Authors have claimed that, with enhanced hydrogen bonding between polymers molecular chains, remarkably, increased mechanical properties could be observed.

Despite the negative impact of Ag and GO, the results of the TS value were higher than those reported by Chen et al. [47] for chitosan/graphene oxide bionanocomposites (55.7 $\pm 1.0 \mathrm{MPa}$ ) or Chen et al. [48] for chitosan/alginate bionanocomposites enhanced with graphene oxide $(29.1 \pm 4.9 \mathrm{MPa})$. Additionally, obtained composites were mechanically stronger than commonly used plastic foils with LDPE (12.4-25.7 MPa) reported by Czarnecka-Komorowska et al. [49].

$\mathrm{Ag}, \mathrm{GO}$ or Ag/GO introduction into the hyaluronic composite reduced its extensibility by 2 to 6 times. In this way, composites with greater stiffness were obtained. Nevertheless, the value of elongation at break for Hyal composites was higher than those reported by Chen et al. [47] regarding chitosan and chitosan/carboxymethyl cellulose films (22.6 and $10 \%$ ). The same authors noted that bionanocomposites of chitosan polyelectrolyte complexed materials with graphene oxide (GO) had lower elongation $(15.3 \%)$ than the control sample (chitosan matrix alone-22.6\%). 
The water contact angle analysis shows that the hyaluronic acid foils without any additive is the most hydrophobic sample (Table 3). The addition of graphene nanoparticles almost does not change the Hyal wettability. On the contrary, the presence of silver nanoparticles switches the sample hydrophobicity range to about $40-50^{\circ}$, which proves at least partial hydrophilic properties for such material. The data from diiodomethane contact angles do not show changes as pronounced the wetting angles tested with water. As seen, all measured values are in the range of $40-55^{\circ}$, and the overall trend of changes cannot be observed.

Table 3. The studied foils' contact angle measured using water and diiodomethane (DIM) and the dispersive, polar and total surface free energies (calculated using the Owen-Wendt method).

\begin{tabular}{|c|c|c|c|c|c|}
\hline & Water & DIM & $\begin{array}{c}\text { Dispersive Energy } \\
\left(\mathrm{mJ} / \mathrm{m}^{2}\right)\end{array}$ & $\begin{array}{l}\text { Polar Energy } \\
\qquad\left(\mathrm{mJ} / \mathrm{m}^{2}\right)\end{array}$ & $\begin{array}{l}\text { Total Surface Free Energy } \\
\qquad\left(\mathrm{mJ} / \mathrm{m}^{2}\right)\end{array}$ \\
\hline Hyal/C & $84.0^{\circ}$ & $41.0^{\circ}$ & 41.59 & 2 & 43.60 \\
\hline Hyal/Ag & $41.0^{\circ}$ & $52.0^{\circ}$ & 23.93 & 33.02 & 56.95 \\
\hline Hyal/GO & $79.5^{\circ}$ & $55.3^{\circ}$ & 30.21 & 6.36 & 36.58 \\
\hline Hyal/Ag/GO & $49.0^{\circ}$ & $43.5^{\circ}$ & 30.64 & 23.29 & 53.93 \\
\hline
\end{tabular}

The further analysis of the surface free energy using the Ownes-Wendt method lets us conclude that graphene nanoparticle addition slightly diminishes hyaluronic acid foils total free surface energy. At the same time, the presence of silver nanoparticles significantly increases the total energy. However, the problem is more complex, and a detailed analysis of polar and dispersive energies must be performed and discussed. Hylauronic acid foils without any additives have the smallest polar energy. The addition of any of the particles increases polar energy in graphene slightly, while it does so significantly for silver. Simultaneously, hyaluronic foil without any particles has the highest dispersive energy, and the situation here is the opposite for polar energy. The addition of any of the particles diminishes the dispersive energy of hyaluronic acid foils. The most substantial effect is observed for foils dotted with only silver particles. In the presence of graphene (alone or in the co-composition with silver), the impact is not so large.

The bacteriostatic activity of different foils was tested with 17 environmental strains of bacteria from the following species: S. saprophyticus $(n=1)$, S. equorum $(n=1)$, B. licheniformis $(n=2), B$. subtilis $(n=1)$ and E. coli $(n=12)$. The results of all individual readouts are shown in Table 4 and summarized in Figure 4. It was observed that nanoparticles Hyal/ Ag and Hyal/Ag/GO caused growth inhibition of bacteria, but to various degrees, depending on the species and strain tested. No growth inhibition zone was observed in the case of Hyal/GO. In the case of Hyal/Ag, the highest mean growth inhibition was observed for Staphylococcus spp. (mean of $18 \mathrm{~mm}$ ), followed by Bacillus spp. (mean of $16.3 \mathrm{~mm}$ ) and E. coli (mean of $13.4 \mathrm{~mm}$ ), while in the case of Hyal/ $\mathrm{Ag} / \mathrm{GO}$ the highest mean growth inhibition was observed for Bacillus spp. (mean of $15.3 \mathrm{~mm}$ ), followed by Staphylococcus spp. $(14.5 \mathrm{~mm})$ and $E$ coli $(13.8 \mathrm{~mm})$. These results suggest higher susceptibility of Gram-positive bacteria (i.e., Staphylococcus spp. and Bacillus spp.) to Hyal/Ag silver nanocomposites than the susceptibility of Gram-negative E. coli. The differences in the susceptibility proved to be statistically significant in the case of Hyal/ $\mathrm{Ag}$ ( $t$-test: $t=3.98 ; p=0.0012)$. 
Table 4. Growth inhibition of bacterial strains tests caused by the silver nanoparticle composites $(\mathrm{mm})$. The results are means of three replicates.

\begin{tabular}{ccccc}
\hline \multirow{2}{*}{ Bacterial Strain } & \multicolumn{4}{c}{ Nanoparticles } \\
\cline { 2 - 5 } & Hyal/Ag * & Hyal/GO & Hyal/Ag/GO & Hyal/C \\
\hline Bacillus licheniformis & 14 & 0 & 16 & 0 \\
Bacillus licheniformis & 17 & 0 & 14 & 0 \\
Bacillus subtilis & 18 & 0 & 16 & 0 \\
Staphylococcus equorum & 17 & 0 & 13 & 0 \\
Staphylococcus saprophyticus & 19 & 0 & 16 & 0 \\
Escherichia coli 1 & 14 & 0 & 12 & 0 \\
Escherichia coli 2 & 15 & 0 & 15 & 0 \\
Escherichia coli 3 & 16 & 0 & 15 & 0 \\
Escherichia coli 4 & 14 & 0 & 15 & 0 \\
Escherichia coli 5 & 15 & 0 & 15 & 0 \\
Escherichia coli 6 & 12 & 0 & 0 & 0 \\
Escherichia coli 7 & 11 & 0 & 15 & 0 \\
Escherichia coli 8 & 14 & 0 & 14 & 0 \\
Escherichia coli 9 & 14 & 0 & 20 & 0 \\
Escherichia coli 10 & 13 & 0 & 17 & 0 \\
Escherichia coli 11 & 12 & 0 & 15 & 0 \\
Escherichia coli 12 & 11 & 0 & 13 & 0 \\
mean & 14.47 & 0 & 14.18 & 0 \\
standard deviation & 2.35 & 0 & 4.07 & 0 \\
coefficient of variation $(\%)$ & 16.23 & - & 28.68 & - \\
\hline
\end{tabular}

* The differences in growth inhibition zones between Gram-positive (Bacillus spp. and Staphylococcus spp.) and Gram-negative bacteria (Escherichia coli) obtained for Hyal/Ag are statistically significant $(t=3.39 ; p=0.0012)$.

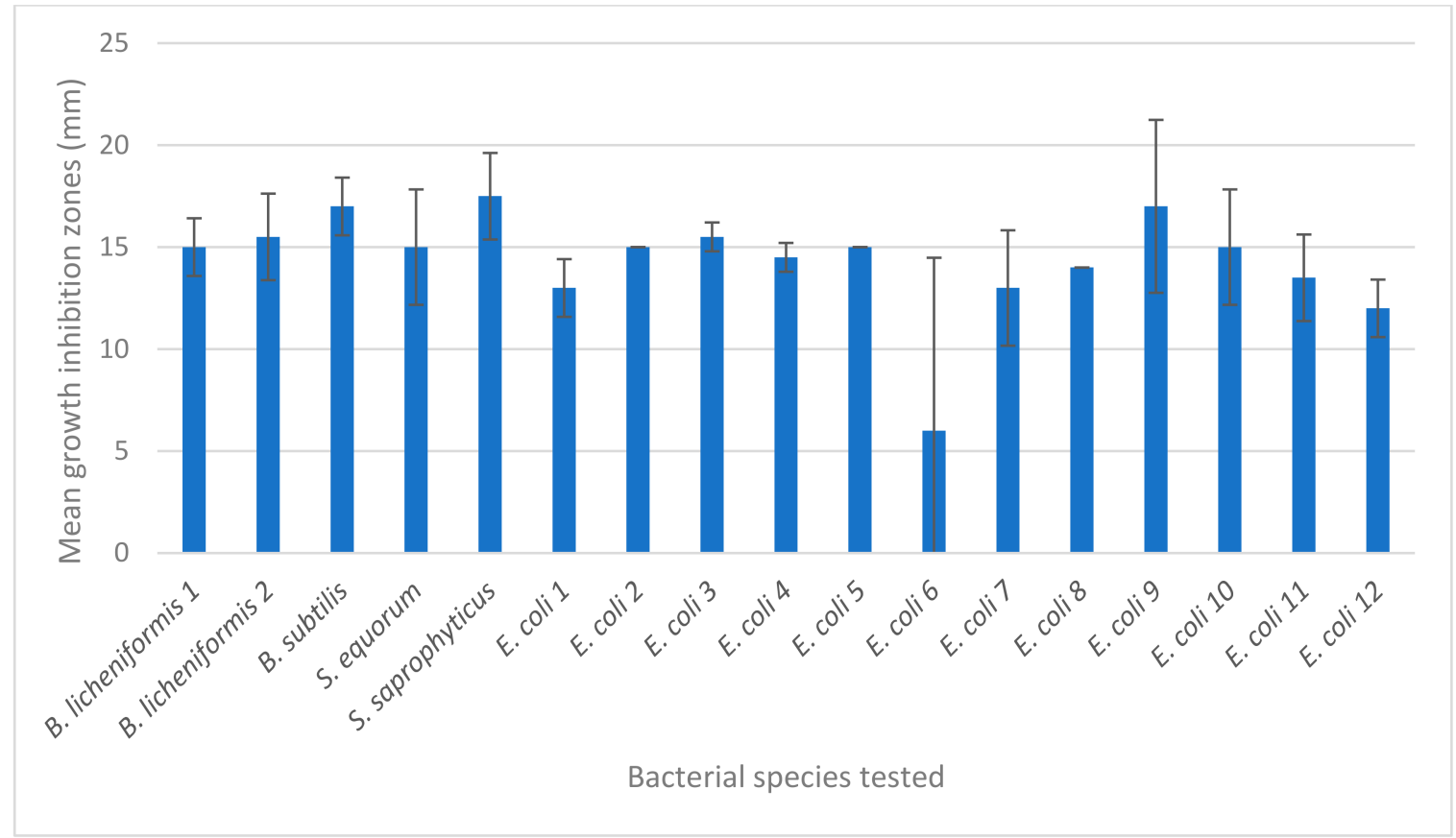

Figure 4. Mean growth inhibition zones (mm) caused by Hyal/Ag and Hyal/Ag/GO silver nanoparticle composites.

The antimicrobial activity of silver has been attributed to certain morphological and physicochemical characteristics, including size, shape, colloidal stabilization, surface corona, composition, aggregation behavior, surface coating, surface/volume ratio, etc., which-when properly used - contribute to the inhibitory potential against several pathogenic microorganisms [50]. The antimicrobial (both antifungal and antibacterial) activity of silver nanoparticles synthesized using a number of various approaches has been 
demonstrated by, e.g., Abbasza-degan et al. [51], Guzman et al. [34], Khatoon et al. [35] and Khatoon et al. [36]. It was observed in some studies, that Gram-positive bacteria (e.g., Staphylococcus spp. or Bacillus spp.) are less susceptible to silver nanoparticles, compared to Gram-negative bacteria, such as E. coli $[35,50]$. The differences in the reaction of those two groups of bacteria to silver nanoparticles have been attributed to, e.g., greater thickness of peptidoglycan layer of Gram-positive bacteria or the presence of negative charge on the peptidoglycan layer that inactivates the bioactive $\mathrm{Ag}^{+}$ions generated from silver nanoparticles [51]. However, growth inhibition zones in the studies by Guzman et al. [34], in which the effect of silver nanoparticles was tested against Gram-positive (S. aureus) and Gram-negative bacteria (E. coli and P. aeruginosa), were larger in the case of S. aureus bacteria than in the case of E. coli and P. aeruginosa, indicating higher susceptibility of the former ones to Ag NPs. These results are consistent with observations made in our study (Table 4 and Figure 5). According to Franci et al. [33], the most essential and most corroborated mechanism of action of Ag NPs against E. coli is the alteration of membrane permeability and respiration, while against $S$. aureus - irreversible damage to bacterial cells occurs. In view of the obtained results, it is reasonable to acknowledge that silver nanoparticles examined in this study are effective against Bacillus spp., Staphylococcus spp. And E. coli, which are potential human pathogens.

In order to investigate the effect of the obtained nanocomposites on human melanoma cells, we performed a Cytotoxicity LDH test and a Crystal Violet Assay. Crystal violet is a triarylmethane dye that binds to ribose type molecules such as DNA in nuclei. The number of the cells dyed with crystal violet is directly proportional to the number of attached cells to the plate, which assumes that they are "alive" The lactate dehydrogenase (LDH) test was performed to assess the toxicity of the tested substance to the cell culture [52]. LDH is a cytosol enzyme, which means that it is not being released to the environment in physiological conditions. When the cell membrane is destroyed or harm causes the death of a cell, it can be found outside the cell. Given that membrane permeability is a key feature of necrotic cells, measuring the release of LDH as a cytosolic enzyme, in combination with other methods, is a useful method for detecting necrosis.

In our study we used the LDH test and the Crystal Violet Assay, which gave us the influence of the nanoparticle composites on the decrease of cell viability excluding their potential necrosis. The results of the LDH test are presented in Table 5 and the cell viabilities are shown in Figure 5.

After $24 \mathrm{~h}$, a $10-18 \%$ decrease in cell viability was observed for all samples containing nanoparticles compared to the negative control (NC) (100\%) and to Hyal/C (Figure 5a). There was no difference between them on the viability of WM-266-4 melanoma cells. After $48 \mathrm{~h}$, a significant decrease in cell viability was observed for all composite samples vs. NC and all results were statistically significant (Figure $5 b$ ). Analyzing the concentrations of nanocomposites used in the study, it can be concluded that with their increase the inhibition of WM-266-4 cell growth increased, with a particular reduction in viability (above 50\%) at the concentrations of 30 and $35 \%$. Among the nanoparticle composites used, the strongest inhibitory effect on the growth of WM-266-4 cells was demonstrated by Hyal/Ag/GO (Figure $5 b$ ), where the range of cell viability reduction ranged from $45 \%$ at the lowest concentration to $62 \%$ at the highest concentration of the used nanocomposite. In the case of Hyal/Ag/GO, the effect of all concentrations (15-35\%) was also statistically significant vs. Hyal/C (Figure $5 b$ ). There was no release of LDH to the cellular medium which indicates no involvement of necrosis in the process of cell death under the influence of $\mathrm{Hyal} / \mathrm{Ag} / \mathrm{GO}$ (Table 5). In the case of Hyal/GO, the decrease in the number of cells was connected with an increase in the LDH concentration in the cell medium, which may indicate the involvement of necrosis in the process of cell death (Table 5). There was no cytonecrotic effect of the remaining Hyal/Ag and Hyal/C nanocomposites on WM-266-4 cells (Table 5). 


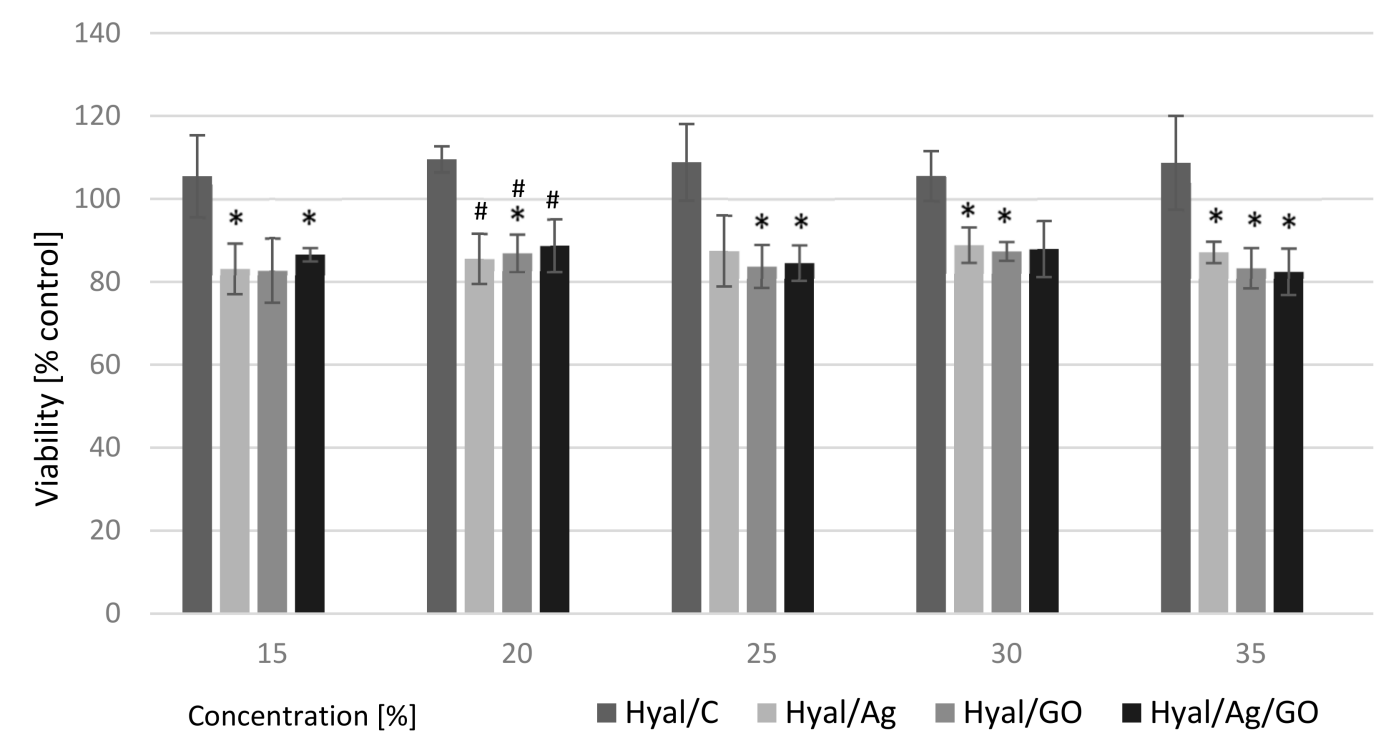

(a)

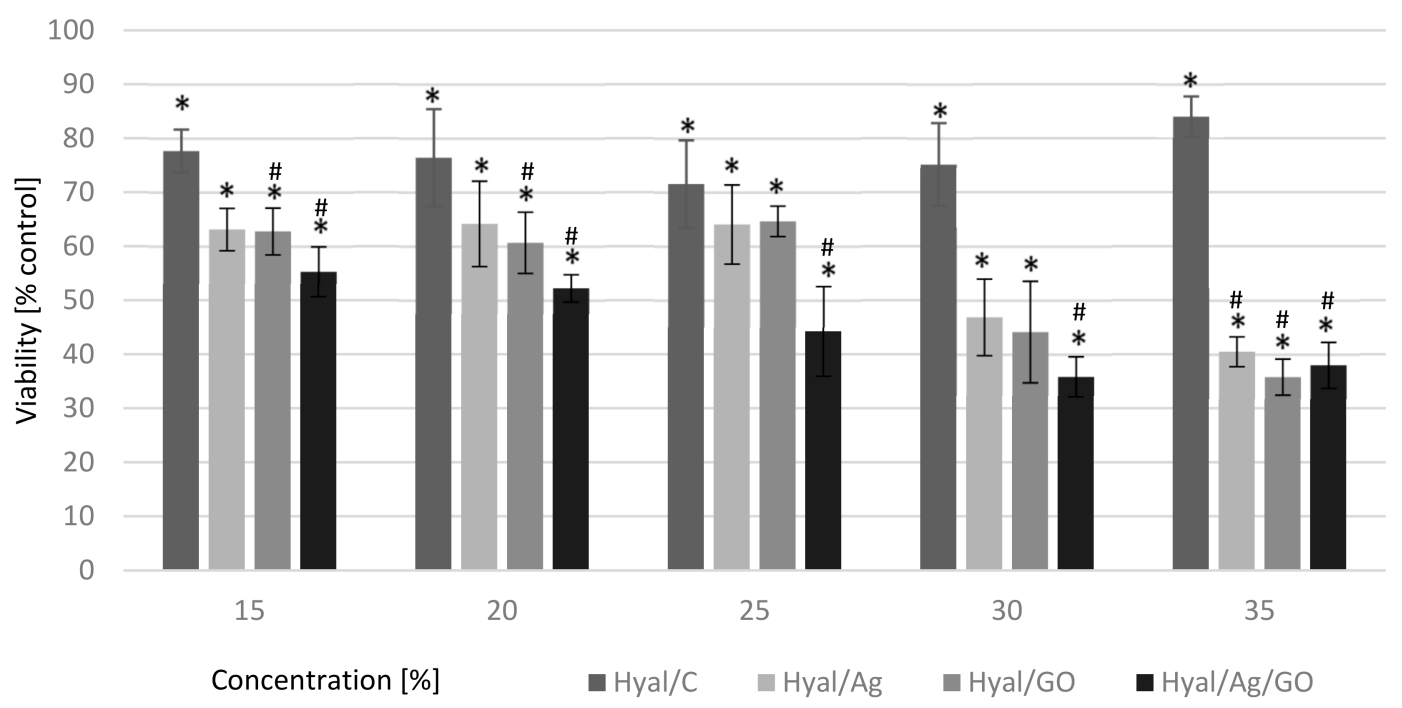

(b)

Figure 5. Effect of nanoparticle composites on WM-266-4 cells viability. WM-266-4 melanoma was seeded on the 96-well plates $(8 \times 103$ cells per well). Twenty-four hours after seeding, the growth medium was replaced with a medium containing nanoparticle composites for (a) $24 \mathrm{~h}$ and (b) $48 \mathrm{~h}$. Values are expressed as mean \pm SD for $n=12$, standardized to untreated control (UC) as $100 \%$. Statistical significance was based on t-test * $p \leq 0.05$ vs. UC and \# $p \leq 0.05$ vs. sodium hyaluronate. 
Table 5. Cytotoxycity of nanoparticle composites on WM-266-4 cells.

\begin{tabular}{|c|c|c|c|c|}
\hline \multicolumn{5}{|c|}{ WM-266-4 Cytotoxicity \% } \\
\hline Concentration & Hyal/C \pm SD & Hyal $/$ Ag \pm SD & Hyal/GO $\pm \mathrm{SD}$ & Hyal/Ag/GO \pm SD \\
\hline \multicolumn{5}{|c|}{$24 \mathrm{~h}$} \\
\hline $15 \%$ & $0.35 \pm 0.023$ & $0.60 \pm 0.043$ & $2.78 \pm 0.023$ & $-1.34 \pm 0.014$ \\
\hline $20 \%$ & $0.84 \pm 0.023$ & $-3.01 \pm 0.049$ & $3.96 \pm 0.023$ & $-1.94 \pm 0.048$ \\
\hline $25 \%$ & $-3.60 \pm 0.033$ & $-2.70 \pm 0.045$ & $22.54 \pm 0.023$ & $-2.91 \pm 0.044$ \\
\hline $30 \%$ & $-3.59 \pm 0.018$ & $2.70 \pm 0.049$ & $12.73 \pm 0.023$ & $-1.12 \pm 0.038$ \\
\hline $35 \%$ & $5.44 \pm 0.033$ & $4.60 \pm 0.025$ & $22.50 \pm 0.023$ & $-3.26 \pm 0.065$ \\
\hline \multicolumn{5}{|c|}{$48 \mathrm{~h}$} \\
\hline $15 \%$ & $-9.39 \pm 0.023$ & $-3.56 \pm 0.055$ & $6.78 \pm 0.033$ & $-3.53 \pm 0.025$ \\
\hline $20 \%$ & $-9.81 \pm 0.022$ & $-3.71 \pm 0.029$ & $19.45 \pm 0.060$ & $-3.03 \pm 0.017$ \\
\hline $25 \%$ & $-10.75 \pm 0.019$ & $-3.99 \pm 0.022$ & $27.40 \pm 0.027$ & $-1.49 \pm 0.069$ \\
\hline $30 \%$ & $-12.03 \pm 0.029$ & $-4.15 \pm 0.065$ & $25.52 \pm 0.015$ & $-1.75 \pm 0.040$ \\
\hline $35 \%$ & $-11.07 \pm 0.041$ & $-4.58 \pm 0.070$ & $33.81 \pm 0.062$ & $-2.04 \pm 0.074$ \\
\hline
\end{tabular}

WM-266-4 melanoma were seeded on the 96-well plates $\left(8 \times 10^{3}\right.$ cells per well). Twenty-four hours later, growth medium was replaced with a medium containing nanoparticle composites. Cytotoxicity was measured with Cytotoxicity Detection Kit LDH (Roche, Poland). Values are expressed as mean $\pm \mathrm{SD}$ for $n=12$, standardized to untreated control (UC) as $100 \%$.

\section{Conclusions}

The preparation of thin, elastic and transparent foils containing silver nanoparticles and graphene oxide in Hyal matrix was successfully carried out using an environmentally friendly method. In the composite containing GO and nanosilver, we could observe a formation of nanocapsules (or nano-bubbles) sized 50-100 $\mathrm{nm}$ with silver nanoparticles sized 10-20 nm regularly distributed inside the bubbles. The results of the structural analysis indicated intermolecular interactions of the functional groups in Hyal and GO with silver nanoparticles. The addition of GO did not improve the mechanical properties of Hyal foils. The results of the measurements of wettability and surface free energy confirmed that the addition of nanoparticles increased the polar energy and decreased the dispersion energy of the sample. Silver nanoparticles affected the sample much more than graphene particles, but when both graphene and silver particles were present in the system, we observed a synergistic effect from both components. Bacteriostatic activity was observed only in the case of Ag-containing nanocomposites, while those containing sodium hyaluronate or graphene/sodium hyaluronate were ineffective against the tested bacteria, i.e., Bacillus spp., Staphylococcus spp. and E. coli. The differences between Hyal/Ag and $\mathrm{Hyal} / \mathrm{Ag} / \mathrm{GO}$ were insignificant, contrary to their effectiveness against tested bacterial species and genera. Gram-positive bacteria (Bacillus spp. and Staphylococcus spp.) proved to be more susceptible to the silver nanocomposites than Gram-negative E. coli. The composites containing graphene oxide and nanosilver/graphene oxide exhibited cytotoxic effects on the tested WM-266-4 human melanoma cell line. The strongest inhibitory effect on cell growth was demonstrated by $\mathrm{Hyal} / \mathrm{Ag} / \mathrm{GO}$ and there was no involvement of necrosis in the process of cell death (which could be observed in the case of Hyal/GO). There was no cytonecrotic effect of the remaining Hyal/Ag and Hyal/C nanocomposites on the tested cells. 
Author Contributions: Conceptualization, K.K. and G.K.; methodology, K.K., G.K., L.K.-F., M.D. and M.K. (Marcel Krzan); formal analysis, K.K., M.K. (Marcel Krzan), M.K. (Magdalena Krystyjan), L.K.-F., A.L.-B., A.K., M.D. and G.K.; investigation, K.K., M.K. (Marcel Krzan) and G.K.; writing-original draft preparation, K.K., L.K., M.K. (Marcel Krzan), M.K. (Magdalena Krystyjan), A.L.-B., A.K. and G.K.; writing-review and editing, K.K., L.K., M.K. (Marcel Krzan) and G.K.; visualization, K.K. and L.K.; supervision, K.K., G.K. and M.K. (Marcel Krzan). All authors have read and agreed to the published version of the manuscript.

Funding: This research was funded by the National Science Centre of Poland, grant no. 2016/21/B/ ST8/02107 to M. Krzan and by a subsidy of the Ministry of Science and Higher Education for the University of Agriculture in Krakow for 2020.

Institutional Review Board Statement: Not applicable.

Informed Consent Statement: Not applicable.

Data Availability Statement: The data presented in this study are available on request from the corresponding author.

Conflicts of Interest: The authors declare no conflict of interest.

\section{References}

1. Cumpstey, I. Chemical Modification of Polysaccharides. ISRN Org. Chem. 2013, 2013, 27. [CrossRef]

2. Li, S.; Xiong, Q.; Lai, X.; Li, X.; Wan, M.; Zhang, J.; Yan, Y.; Cao, M.; Lu, L.; Guan, J.; et al. Molecular Modification of Polysaccharides and Resulting Bioactivities. Compr. Rev. Food Sci. Food Saf. 2016, 15, 237-250. [CrossRef] [PubMed]

3. Gamal-Eldeen, A.M.; Ahmed, E.F.; Abo-Zeid, M.A. In vitro cancer chemopreventive properties of polysaccharide extract from the brown alga, Sargassum latifolium. Food Chem. Toxicol. 2009, 47, 1378-1384. [CrossRef] [PubMed]

4. Tian, Y.; Zeng, H.; Xu, Z.; Zheng, B.; Lin, Y.; Gan, C.; Lo, Y.M. Ultrasonic-assisted extraction and antioxidant activity of polysaccharides recovered from white button mushroom (Agaricus bisporus). Carbohydr. Polym. 2012, 88, 522-529. [CrossRef]

5. Li, S.; Shah, N.P. Antioxidant and antibacterial activities of sulphated polysaccharides from Pleurotus eryngii and Streptococcus thermophilus ASCC 1275. Food Chem. 2014, 165, 262-270. [CrossRef] [PubMed]

6. Martínez, A.M.; Benito, M.; Pérez, E.; María Teijón, J.; Dolores Blanco, M. The Role of Anionic Polysaccharides in the Preparation of Nanomedicines with Anticancer Applications. Curr. Pharm. Des. 2016, 22, 3364-3379. [CrossRef] [PubMed]

7. Darder, M.; Aranda, P.; Ruiz-Hitzky, E. Bionanocomposites: A new concept of ecological, bioinspired, and functional hybrid materials. Adv. Mater. 2007, 19, 1309-1319. [CrossRef]

8. Dias, A.M.G.C.; Hussain, A.; Marcos, A.S.; Roque, A.C.A. A biotechnological perspective on the application of iron oxide magnetic colloids modified with polysaccharides. Biotechnol. Adv. 2011, 29, 142-155. [CrossRef]

9. Hanemann, T.; Szabó, D.V. Polymer-Nanoparticle Composites: From Synthesis to Modern Applications. Materials 2010, 3, 3468-3517. [CrossRef]

10. Emam, H.E.; Ahmed, H.B. Polysaccharides templates for assembly of nanosilver. Carbohydr. Polym. 2016, 135, 300-307. [CrossRef]

11. Yang, C.H.; Wang, L.S.; Chen, S.Y.; Huang, M.C.; Li, Y.H.; Lin, Y.C.; Chen, P.F.; Shaw, J.F.; Huang, K.S. Microfluidic assisted synthesis of silver nanoparticle-chitosan composite microparticles for antibacterial applications. Int. J. Pharm. 2016, 510, 493-500. [CrossRef]

12. Kemp, M.M.; Kumar, A.; Clement, D.; Ajayan, P.; Mousa, S.; Linhardt, R.J. Hyaluronan- and heparin-reduced silver nanoparticles with antimicrobial properties. Nanomedicine 2009, 4, 421-429. [CrossRef]

13. Khachatryan, G.; Khachatryan, K.; Stobinski, L.; Tomasik, P.; Fiedorowicz, M.; Lin, H.M. CdS and ZnS quantum dots embedded in hyaluronic acid films. J. Alloys Compd. 2009, 481, 402-406. [CrossRef]

14. Price, R.D.; Berry, M.G.; Navsaria, H.A. Hyaluronic acid: The scientific and clinical evidence. J. Plast. Reconstr. Aesthetic Surg. 2007, 60, 1110-1119. [CrossRef]

15. Allison, D.D.; Grande-Allen, K.J. Hyaluronan: A powerful tissue engineering tool. Tissue Eng. 2006, 12, 2131-2140. [CrossRef]

16. Akhavan, O.; Ghaderi, E.; Aghayee, S.; Fereydooni, Y.; Talebi, A. The use of a glucose-reduced graphene oxide suspension for photothermal cancer therapy. J. Mater. Chem. 2012, 22, 13773-13781. [CrossRef]

17. Liu, Z.; Robinson, J.T.; Sun, X.; Dai, H. PEGylated nanographene oxide for delivery of water-insoluble cancer drugs. J. Am. Chem. Soc. 2008, 130, 10876-10877. [CrossRef]

18. Si, Y.; Samulski, E.T. Synthesis of water soluble graphene. Nano Lett. 2008, 8, 1679-1682. [CrossRef]

19. Bao, H.; Pan, Y.; Ping, Y.; Sahoo, N.G.; Wu, T.; Li, L.; Li, J.; Gan, L.H. Chitosan-functionalized graphene oxide as a nanocarrier for drug and gene delivery. Small 2011, 7, 1569-1578. [CrossRef]

20. Luo, Y.; Cai, X.; Li, H.; Lin, Y.; Du, D. Hyaluronic Acid-Modified Multifunctional Q-Graphene for Targeted Killing of DrugResistant Lung Cancer Cells. ACS Appl. Mater. Interfaces 2016, 8, 4048-4055. [CrossRef]

21. Naahidi, S.; Jafari, M.; Edalat, F.; Raymond, K.; Khademhosseini, A.; Chen, P. Biocompatibility of engineered nanoparticles for drug delivery. J. Control. Release 2013, 166, 182-194. [CrossRef] [PubMed] 
22. Fan, L.; Ge, H.; Zou, S.; Xiao, Y.; Wen, H.; Li, Y.; Feng, H.; Nie, M. Sodium alginate conjugated graphene oxide as a new carrier for drug delivery system. Int. J. Biol. Macromol. 2016, 93, 582-590. [CrossRef] [PubMed]

23. Jung, H.S.; Lee, M.Y.; Kong, W.H.; Do, I.H.; Hahn, S.K. Nano graphene oxide-hyaluronic acid conjugate for target specific cancer drug delivery. RSC Adv. 2014, 4, 14197-14200. [CrossRef]

24. Song, E.; Han, W.; Li, C.; Cheng, D.; Li, L.; Liu, L.; Zhu, G.; Song, Y.; Tan, W. Hyaluronic acid-decorated graphene oxide nanohybrids as nanocarriers for targeted and $\mathrm{pH}$-responsive anticancer drug delivery. ACS Appl. Mater. Interfaces 2014, 6, 11882-11890. [CrossRef]

25. Dantas, P.C.d.L.; Martins-Júnior, P.A.; Coutinho, D.C.O.; Andrade, V.B.; Valverde, T.M.; Ávila, E.d.S.; Almeida, T.C.S.; QueirozJunior, C.M.; Sá, M.A.; Góes, A.M.; et al. Nanohybrid composed of graphene oxide functionalized with sodium hyaluronate accelerates bone healing in the tibia of rats. Mater. Sci. Eng. C 2021, 123. [CrossRef]

26. Xu, C.; Wang, X.; Zhu, J. Graphene-Metal particle nanocomposites. J. Phys. Chem. C 2008, 112, 19841-19845. [CrossRef]

27. Wang, W.; Wang, W.; Chen, X.; Wu, Y.; Dong, L. Synthesis and characterization of Ag/graphene nano-composite. Xiyou Jinshu Cailiao Yu Gongcheng/Rare Met. Mater. Eng. 2015, 44, 2138-2142. [CrossRef]

28. Shen, J.; Shi, M.; Li, N.; Yan, B.; Ma, H.; Hu, Y.; Ye, M. Facile synthesis and application of Ag-chemically converted graphene nanocomposite. Nano Res. 2010, 3, 339-349. [CrossRef]

29. Ge, L.; Li, Q.; Wang, M.; Ouyang, J.; Li, X.; Xing, M.M.Q. Nanosilver particles in medical applications: Synthesis, performance, and toxicity. Int. J. Nanomed. 2014, 9, 2399.

30. Wei, L.; Lu, J.; Xu, H.; Patel, A.; Chen, Z.S.; Chen, G. Silver nanoparticles: Synthesis, properties, and therapeutic applications. Drug Discov. Today 2015, 20, 595-601. [CrossRef]

31. Lee, H.-S.; Ryu, D.-S.; Choi, S.-J.; Lee, D.-S. Antibacterial Activity of Silver-Nanoparticles Against Staphylococcus aureus and Escherichia coli. Microbiol. Biotechnol. Lett. 2011, 39, 77-85.

32. Lenart-Boron'1, A.; Boron'1, B.; Lenart-Boroń, A. Antimicrobial resistance and prevalence of extended-spectrum beta-lactamase genes in Escherichia coli from major rivers in Podhale, southern Poland. Int. J. Environ. Sci. Technol. 2017, 14, 241-250. [CrossRef]

33. Franci, G.; Falanga, A.; Galdiero, S.; Palomba, L.; Rai, M.; Morelli, G.; Galdiero, M. Silver nanoparticles as potential antibacterial agents. Molecules 2015, 20, 8856-8874. [CrossRef]

34. Guzman, M.; Dille, J.; Godet, S. Synthesis and antibacterial activity of silver nanoparticles against gram-positive and gramnegative bacteria. Nanomed. Nanotechnol. Biol. Med. 2012, 8, 37-45. [CrossRef]

35. Khatoon, U.T.; Nageswara Rao, G.V.S.; Mohan, K.M.; Ramanaviciene, A.; Ramanavicius, A. Antibacterial and antifungal activity of silver nanospheres synthesized by tri-sodium citrate assisted chemical approach. Vacuum 2017, 146, 259-265. [CrossRef]

36. Khatoon, U.T.; Rao, G.V.S.N.; Mohan, M.K.; Ramanaviciene, A.; Ramanavicius, A. Comparative study of antifungal activity of silver and gold nanoparticles synthesized by facile chemical approach. J. Environ. Chem. Eng. 2018, 6, 5837-5844. [CrossRef]

37. Khachatryan, G.; Khachatryan, K.; Grzyb, J.; Fiedorowicz, M. Formation and properties of hyaluronan/nano Ag and hyaluronanlecithin/nano Ag films. Carbohydr. Polym. 2016, 151. [CrossRef]

38. Khachatryan, G.; Khachatryan, K.; Krystyjan, M.; Krzan, M.; Khachatryan, L. Functional properties of composites containing silver nanoparticles embedded in hyaluronan and hyaluronan-lecithin matrix. Int. J. Biol. Macromol. 2020, 149, 417-423. [CrossRef]

39. Stobinski, L.; Lesiak, B.; Malolepszy, A.; Mazurkiewicz, M.; Mierzwa, B.; Zemek, J.; Jiricek, P.; Bieloshapka, I. Graphene oxide and reduced graphene oxide studied by the XRD, TEM and electron spectroscopy methods. J. Electron Spectros. Relat. Phenomena 2014, 195, 145-154. [CrossRef]

40. Owens, D.K.; Wendt, R.C. Estimation of the surface free energy of polymers. J. Appl. Polym. Sci. 1969, 13, 1741-1747. [CrossRef]

41. Rudawska, A.; Jacniacka, E. Analysis for determining surface free energy uncertainty by the Owen-Wendt method. Int. J. Adhes. Adhes. 2009, 29, 451-457. [CrossRef]

42. Nowak, N.; Grzebieniarz, W.; Khachatryan, G.; Khachatryan, K.; Konieczna-Molenda, A.; Krzan, M.; Grzyb, J. Synthesis of Silver and Gold Nanoparticles in Sodium Alginate Matrix Enriched with Graphene Oxide and Investigation of Properties of the Obtained Thin Films. Appl. Sci. 2021, 11, 3857. [CrossRef]

43. Jiang, S.; Liu, C.; Wang, X.; Xiong, L.; Sun, Q. Physicochemical properties of starch nanocomposite films enhanced by selfassembled potato starch nanoparticles. LWT Food Sci. Technol. 2016, 69, 251-257. [CrossRef]

44. Krystyjan, M.; Khachatryan, G.; Ciesielski, W.; Buksa, K.; Sikora, M. Preparation and characteristics of mechanical and functional properties of starch/Plantago psyllium seeds mucilage films. Starch/Staerke 2017, 69, 1700014. [CrossRef]

45. Liu, Y.; Yuan, Y.; Duan, S.; Li, C.; Hu, B.; Liu, A.; Wu, D.; Cui, H.; Lin, L.; He, J.; et al. Preparation and characterization of chitosan films with three kinds of molecular weight for food packaging. Int. J. Biol. Macromol. 2020, 155, 249-259. [CrossRef] [PubMed]

46. Sharma, A.; Mandal, T.; Goswami, S. Fabrication of cellulose acetate nanocomposite films with lignocelluosic nanofiber filler for superior effect on thermal, mechanical and optical properties. Nano-Struct. Nano-Objects 2021, 25. [CrossRef]

47. Chen, P.; Xie, F.; Tang, F.; McNally, T. Thermomechanical-induced polyelectrolyte complexation between chitosan and carboxymethyl cellulose enabling unexpected hydrolytic stability. Compos. Sci. Technol. 2020, 189. [CrossRef]

48. Chen, P.; Xie, F.; Tang, F.; McNally, T. Graphene oxide enhanced ionic liquid plasticisation of chitosan/alginate bionanocomposites. Carbohydr. Polym. 2021, 253, 117231. [CrossRef]

49. Czarnecka-Komorowska, D.; Wiszumirska, K.; Garbacz, T. Films Ldpe/Lldpe Made from Post—Consumer Plastics: Processing, Structure, Mechanical Properties. Adv. Sci. Technol. Res. J. 2018, 12, 134-142. [CrossRef] 
50. Prasher, P.; Singh, M.; Mudila, H. Silver nanoparticles as antimicrobial therapeutics: Current perspectives and future challenges. 3 Biotech 2018, 8, 411. [CrossRef] [PubMed]

51. Abbaszadegan, A.; Ghahramani, Y.; Gholami, A.; Hemmateenejad, B.; Dorostkar, S.; Nabavizadeh, M.; Sharghi, H. The effect of charge at the surface of silver nanoparticles on antimicrobial activity against gram-positive and gram-negative bacteria: A preliminary study. J. Nanomater. 2015, 2015. [CrossRef]

52. Legrand, C.; Bour, J.M.; Jacob, C.; Capiaumont, J.; Martial, A.; Marc, A.; Wudtke, M.; Kretzmer, G.; Demangel, C.; Duval, D.; et al. Lactate dehydrogenase (LDH) activity of the number of dead cells in the medium of cultured eukaryotic cells as marker. $J$. Biotechnol. 1992, 25, 231-243. [CrossRef] 